\title{
A inserção de gênero na educação infantil: a experiência de Portugal - entrevista com Maria João Cardona
}

\section{Resumo}

Cláudia Vianna ${ }^{1}$

ORCID: http://orcid.org/0000-0002-9366-4417

Carolina Faria Alvarenga ${ }^{1}$

0 objetivo desta entrevista é oferecer subsídios para problematizar a introdução da perspectiva de gênero nas políticas de educação com base na experiência bem-sucedida de Portugal, mais enfaticamente na educação infantil e nos anos iniciais do Ensino Fundamental, o que corresponde ao $1^{\circ}$ ciclo da educação básica portuguesa. A entrevista foi concedida pela professora Maria João Cardona às professoras Carolina Faria Alvarenga e Cláudia Vianna, a partir de um debate realizado ora por e-mail, ora presencialmente durante estágio de doutorado ${ }^{2}$, a fim de conhecer as políticas públicas de gênero para a educação de infância portuguesa. Apesar de números ainda desiguais no que tange à igualdade de gênero, Portugal vem, ao longo dos anos, construindo políticas públicas que colocam a educação como área estratégica no combate às desigualdades de gênero. Maria João Cardona ganha destaque ao integrar todo o processo de introdução das questões de gênero e cidadania na educação infantil e no $1^{\circ}$ ciclo da educação básica em Portugal, coordenando a elaboração do Guião de Educação - Gênero e Cidadania - préescolar, considerado um marco histórico na inserção da educação de infância nas políticas de igualdade. Maria João Cardona é educadora de infância, psicóloga e formadora de educadoras de infância e professoras/es do $1^{\circ}$ ciclo da educação básica em Portugal. Tem mestrado e doutorado em Ciências da Educação, realizados na França, em uma perspectiva da sociologia da educação. A partir da experiência em muitos projetos para a educação de infância, que incluem produção de material e formação docente na articulação das políticas de igualdade e políticas de educação, ela oferece um relato inspirador a respeito de como é possível articular as questões de gênero com as dimensões institucionais, políticas e práticas na proposição de um referencial nacional para a educação de infância em Portugal.

\section{Palavras-chave}

Gênero - Educação infântil - Políticas públicas - Cidadania.

1 - Universidade de São Paulo, São Paulo, SP, Brasil. Contatos: cpvianna@usp.br; carol_alvarenga@ded.ufla.br.

2- 0 estágio ocorreu entre julho de 2017 e janeiro de 2018 e insere-se na pesquisa de doutorado em andamento de Carolina Faria Alvarenga, sob orientação da Profa. Dra. Cláudia Pereira Vianna. 


\section{The insertion of gender in early childhood education: the experience of Portugal - interview with Maria João Cardona}

\section{Abstract}

The purpose of this interview is to offer contribution to problematize the introduction of gender's perspective in education policies based on the successful experience of Portugal, more specifically the early childhood education and the early years of Elementary Education, which correspond to the 1st cycle of basic education in Portugal. The interview was conceded by Professor Maria João Cardona to professors Carolina Faria Alvarenga and Claudia Vianna, based on discussions via e-mail, and sometimes in person during doctoral training, in order to know gender public policies for the Portuguese childhood education. Despite the still uneven numbers regarding gender equality, over the years Portugal has been building public policies that place education as a strategic area in the struggle against gender inequalities. Professor Maria João Cardona stands out in the entire process of introducing gender and citizenship issues in early childhood and first cycle of basic education in Portugal, by coordinating the elaboration of the Education Guide - Gender and Citizenship - preschool, considered a historical landmark in the insertion of childhood education into equality policies. Professor Maria João Cardona is a childhood educator, a psychologist and a trainer of early childhood and basic education teachers in Portugal. She has master and doctorate degrees in Educational Sciences, held in France, based on sociology of education. Drawing on experience in many projects for early childhood education - which includes material production and teacher training in the articulation of equality policies and education policies - she provides an inspiring account of how gender issues can be articulated with institutional dimensions, policies and practices in proposing a national referential for early childhood education in Portugal.

\section{Keywords}

Gender - Childhood education - Public policies - Citizenship.

\section{Apresentação}

Maria João Cardona é professora coordenadora do Departamento de Educação e Currículo da Escola Superior de Educação (ESE) do Instituto Politécnico de Santarém - Portugal. Atuou como educadora de infância ${ }^{3}$ entre os anos de 1980 e 1984. Tem

3 - Em Portugal, a Educação Infantil é nomeada educação de infância e as profissionais que trabalham nesta etapa são chamadas de educadoras de infância. Além de mantermos essa nomenclatura, optamos por transcrever as falas da professora Maria João Cardona segundo as normas portuguesas. 
graduação em Psicologia, pela Universidade de Lisboa - Portugal, e mestrado e doutorado em Ciências da Educação, pela Universidade de Caen - França, sob orientação do professor Louis Marmoz.

Optou por estudar na França em uma época em que as Ciências da Educação ainda não tinham se consolidado em Portugal. Durante o mestrado, foi coorientada pelo professor Albano Estrela, da Universidade de Lisboa, um dos pioneiros desta área em Portugal. 0 contato com pesquisadores/as franceses/as possibilitou o acesso a uma vasta literatura a respeito da formação e educação de infância que ainda não havia em Portugal, além da ampliação de seu olhar acerca das práticas educativas com as crianças para uma dimensão institucional e política (CARDONA, 2017, 2018).

Sua aproximação com as questões de gênero inicia-se na década de 1990. Ao trabalhar com a educação de infância, percebe que era preciso ampliar o debate para as mulheres e, com isso, inicia uma relação com a Comissão para a Cidadania e Igualdade de Gênero (CIG), na época denominada Comissão para a Igualdade e para os Direitos das Mulheres (CIDM).

Sensível aos desafios de novos tempos, coordenou, entre 1998 e 2001, a equipe da ESE de Santarém no Projeto Coeducação, um projeto-piloto transnacional, desenvolvido pela CIDM e subvencionado pela Comissão Europeia, envolvendo várias instituições de formação, com a finalidade de promover a integração da dimensão da igualdade de oportunidades entre mulheres e homens na formação docente. Neste projeto, publicou, em coautoria, o caderno "A narrativa na promoção da igualdade de género. Contributos para a educação pré-escolar” (SILVA et al., 2006).

A partir deste projeto, a educação pré-escolar foi considerada uma etapa estratégica para se avançar na construção de materiais destinados à formação docente e de apoio às práticas pedagógicas de educadoras e educadores de infância. Publicado em 2010 e reeditado em 2015, o Guião Educação - Gênero e Cidadania - pré-escola, coordenado por Cardona (CARDONA et al., 2015a), foi considerado um exemplo de boas práticas pela Comissão de Educação da União Europeia, junto com o Guião do $3^{\circ}$ ciclo (CARDONA, et al., 2015b) - o que equivale aos anos finais do Ensino Fundamental no Brasil -, os primeiros a serem lançados entre todos os níveis de ensino.

Os Guiões integram um projeto nacional coordenado pela CIG, que teve como principal finalidade promover a formação, a pesquisa e a construção de materiais para trabalhar as questões de gênero em uma perspectiva de educação para a cidadania na educação básica portuguesa.

Atualmente, Cardona atua nos cursos de formação inicial e continuada docente de educação de infância e $1^{\circ}$ ciclo (licenciatura e mestrado); como docente colaboradora no Doutoramento sobre Formação de Educadores e Professores para as primeiras idades da Universidade de Lisboa; como orientadora de estágios de doutorado e pós-doutorado na área de Educação de Infância e/ou gênero. Pertence ao Centro de Investigação de Estudos da Criança (CIEC), da Universidade do Minho, Braga - Portugal. Coordena, desde 2010, a participação da ESE de Santarém no Chair da Unesco sobre Gender equality and women's empowerment, da Universidade de Chipre.

A proposta, nesta entrevista, de problematizar com Maria João Cardona a inserção de gênero na educação de infância fundamenta-se no destaque de Portugal na construção 
de políticas públicas de educação com foco no combate às desigualdades de gênero, além de ações que envolvem outros setores sociais, como a violência doméstica, a igualdade salarial, a conciliação entre trabalho doméstico e assalariado.

$\mathrm{Na}$ contramão desse movimento, no Brasil, vivemos um momento histórico de retrocesso político, econômico e social, por meio de um cerceamento das políticas sociais, em especial, do congelamento dos investimentos nas áreas de educação e saúde para os próximos vinte anos. Neste contexto, há ainda uma onda conservadora organizada contra o pseudoconceito de ideologia de gênero, em ascensão, que, junto a parlamentares, têm tramitado projetos de lei em que cerceiam, limitam ou excluem os direitos sociais já adquiridos (VIANNA, 2018).

Nesse sentido, considerando as especificidades de cada país, a experiência de Portugal pode trazer-nos pistas de como as questões de gênero foram inseridas nas políticas públicas, o que avançou nos últimos anos, quais ainda são os desafios a enfrentar e as possíveis estratégias a construir.

\section{Referências}

CARDONA, Maria João. A educação de infância: primeira etapa no processo de formação ao longo da vida. In: PORTUGAL. Conselho Nacional de Educação. Organização do Sistema Educativo. Lei de bases do sistema educativo: Balanço e prospetiva. v. 1. Lisboa: CNE, 2017. p. 361. Encontro Organização do Sistema Educativo.

CARDONA, Maria João. Quinze anos depois: o impacto do doutoramento realizado em Caen. In: OLIVEIRA, Dolandina (Org.) Construindo investigação em ciências da educação: os doutoramentos portugueses com Louis Marmoz, Lisboa: Educa, 2018. p. 153-169.

CARDONA, Maria João et al. Guião de educação: género e cidadania no pré-escolar. 2. ed. Lisboa: ClG, 2015a. CARDONA, Maria João et al. Guião de educação: género e cidadania no $1^{\circ}$ ciclo do ensino básico. 2. ed. Lisboa: CIG, 2015b.

SILVA, Ana da. A narrativa na promoção da igualdade de género: contributos para a educação préescolar. Lisboa: CIDM, 2006. (Projecto Coeducação).

VIANNA, Cláudia. Políticas de educação, gênero e diversidade sexual: breve história de lutas, danos e resistências. Belo Horizonte: Autêntica, 2018. 


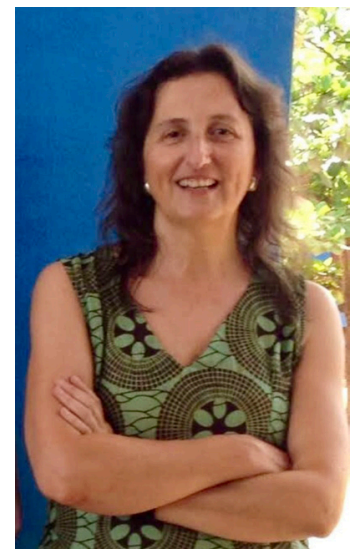

Fonte: Arquivos da entrevistada

\section{Entrevista}

Maria João Cardona, agradecemos por nos conceder esta entrevista. Sabemos de sua importante atuação na educação de infância em Portugal e de seu pioneirismo na defesa de uma educação ancorada na igualdade de gênero. Gostaríamos que nos contasse um pouco sobre sua trajetória acadêmica e profissional.

Bom, já são muitos anos. Começo por destacar minha formação de base como educadora de infância. Fiz o curso de educadora, ao mesmo tempo em que iniciei minha formação como psicóloga, na faculdade. Fiz as duas formações ao mesmo tempo porque, na altura, a Faculdade de Psicologia estava fechada e também porque ainda não sabia muito o que queria. Mas acabei por dar sempre prioridade à Educação de Infância. Depois da licenciatura em Psicologia, fiz os meus estudos de Pós-Graduação em França. Na altura, o professor Albano Estrela tinha projectos ligados à Universidade de Caen, porque as Ciências da Educação estavam já em grande desenvolvimento em França. Em Portugal, estavam ainda a começar. Fiz o equivalente ao Mestrado (DEA - Diplôme d'Études Approfondies) e, mais tarde, o Doutoramento, na área das Ciências da Educação, mas sempre com preocupações na Educação de Infância, nas políticas relacionadas com a infância, nas primeiras idades, e também com a formação.

Apesar de, inicialmente, sua área de pesquisa ser avaliação e currículo da educação de infância, e não gênero, como você se tornou uma parceira importante dos órgãos governamentais na construção de políticas públicas que articulam educação de infância e gênero?

Nas pesquisas que realizei, sempre me preocupei em estudar as políticas educativas, mesmo partindo do estudo da avaliação e do currículo. Talvez por ter tido dois orientadores no mestrado: o professor Marmoz, da Universidade de Caen, em França, e o professor Albano Estrela, das Ciências da Educação, da Universidade de Lisboa. Com o professor Estrela, aprendi a focar o estudo mais na sala de aula, na observação do grupo.

Na França, fui aprendendo a valorizar mais a dimensão institucional e política, a perceber que tudo o que se passa na sala de aula é sempre condicionado pelas políticas educativas. Percebi que não era suficiente estudar apenas o que se passava dentro da sala de aula ou dentro da sala de jardim de infância. Tinha de dar um salto político para perceber por que é que as pessoas trabalhavam de determinada maneira. Por exemplo, uma das minhas preocupações era que as educadoras de infância - eram só mulheres, quando eu fiz os primeiros estudos - tinham todas o mesmo discurso sobre o que deveriam ser as práticas educativas, mas quando eu ia fazer a observação de seu trabalho, verificava que havia muitas diferenças. E comecei a tentar perceber esta diferença entre o discurso e as práticas. Esta diferença não se podia explicar apenas pela formação, pois verifıcava-se nas várias 
gerações de educadoras com que trabalhei. E questionei-me: "Como formadora, como é que eu posso fazer com que as minhas alunas tenham um discurso mais coerente com as suas práticas?" Foi muito importante o trabalho com o professor Albano Estrela, mas faltava uma dimensão institucional e política para poder compreender melhor esta questão.

Foi com a ajuda do professor Marmoz que dei o salto para a dimensão institucional e política. Um salto tão grande que me obrigou a estudar a história da Educação de Infância em Portugal, para perceber o que estava por detrás da organização daquele discurso pedagógico que se tinha generalizado para todas as educadoras. Este discurso integrava os princípios definidos nos primeiros Estatutos dos Jardins de Infância da Rede Pública do Ministério da Educação, criada em 1977, já depois da Revolução dos Cravos de Abril de 1974. Era um documento mais pedagógico do que normativo. Tinha um discurso tão pedagógico, que acabou por servir de base ao trabalho feito no âmbito da formação de educadoras e educadores. Daí o verificar-se uma tão grande homogeneidade a nível do discurso que nem sempre correspondia às práticas realizadas. Foi uma primeira etapa que me mobilizou a estudar a influência da formação e também dos contextos em que as pessoas trabalhavam. Foi meu ponto de partida como investigadora.

0 trabalho que fiz para o DEA foi estudar a história da Educação de Infância, perceber como é que o discurso pedagógico sobre a educação de infância se tinha organizado. Fui recuar no tempo, pois não havia muitos trabalhos sobre esta história. Eu queria compreender, sobretudo, o impacto da revolução do 25 de abril, mas acabei por precisar de recuar mais, para perceber o que já existia antes de 1974. Fui recuando e acabei por começar pelo início, na criação da primeira instituição de Educação de Infância, ainda durante a monarquia.

Optei por começar a estudar a construção do discurso oficial, político, através da análise dos instrumentos reguladores. E, só mais tarde, já no doutoramento, fui fazer entrevistas para perceber melhor como este discurso oficial foi sendo apropriado pelas educadoras. E queria continuar, ter ido mais longe, mas meu orientador disse que já era demais, porque existe muita documentação e houve muitos protagonistas, não só da área educativa, que foi a que estudei, mas também da área da saúde e da área social.

Não se pode ver a infância, a Educação de Infância, como uma questão só das crianças e só da educação. Foi aí que começou minha sensibilização para as questões das mulheres e a minha ligação à Comissão para a Cidadania e Igualdade de Género (CIG) que na altura se chamava CIDM (Comissão para a Igualdade e para os Direitos das Mulheres). Comecei a ir ao Centro de Documentação, a falar com as pessoas, a perceber melhor o trabalho que faziam. Foi o meu primeiro contato.

Descobri imensas imprecisões políticas quando fiz este estudo sobre a história da educação de infância e acabei por ir mais longe do que os objetivos que no início tinha previsto. Por exemplo, tive de analisar os dados estatísticos que, na altura, estavam disponíveis e estudei mais em detalhe o distrito de Santarém, porque é perto de Lisboa, e também, porque é onde trabalho e tinha um acesso mais fácil aos serviços regionais. $\mathrm{E}$ o que descobri? Que os dados estatísticos estavam errados. Tudo errado, não, mas havia muitas lacunas e erros. Observei, por exemplo, que existiam zonas do distrito de Santarém em que a cobertura institucional era maior do que o número de crianças! Quer dizer, quando criaram a rede pública criaram mais jardins do que os que eram necessários. E em 
alguns casos nas estatísticas constavam jardins de infância que verifiquei nunca terem chegado a ser construídos!

Esta disparidade entre os relatórios estatísticos e a realidade deu-me a ideia de fazer um projeto mais detalhado a respeito da realidade do distrito de Santarém para entender melhor as contradições entre os relatórios oficiais. Fiz esse trabalho depois de terminar o DEA e foi o meu primeiro projeto financiado. Consegui apoio da Fundação Gulbenkian e o meu orientador disse: "isto é mais importante do que fazer já o doutoramento" que, na altura, ainda não era obrigatório para a minha carreira.

Tinha tempo, ainda era nova e com o acordo do Prof. Marmoz decidi que era boa ideia fazer uma caracterização mais aprofundada da Educação de Infância no distrito de Santarém, na sequência do estudo da história e dos dados que tinha recolhido durante o DEA. Fiz, com uma equipe da minha instituição, esta pesquisa a respeito da realidade da Educação de Infância no distrito de Santarém.

Esse estudo chamou-se PROCEPE [Projecto de Caracterização da Educação Pré-Escolar] (PROCEPE, 2000). Estudámos tudo o que tinha a ver com a Educação, com a Saúde, com a Segurança Social. Temos vários encontros registrados, há vários livros e artigos. Este estudo foi citado em um Parecer do Conselho Nacional de Educação, elaborado pelo prof. João Formosinho (1995) e, em um estudo da OCDE (2000), foi considerado como a primeira pesquisa em Portugal a ter impacto na tomada de decisões políticas na área da Educação de Infância.

Durante este projeto, aprofundei minha relação com a CIG [então CIDM], porque a Comissão tinha muitos dados de estudos feitos após o 25 de abril. Foi um período muito rico porque, de facto, este projeto foi a base para fazer muitas pontes e perceber porque havia tantas disparidades e tantas contradições no âmbito da Educação de Infância. As publicações do PROCEPE e a publicação da minha tese de Mestrado [DEA] foram muito citadas, pois havia poucos trabalhos sobre a realidade recente da Educação de Infância.

Este estudo foi feito antes da reforma do pré-escolar, em 1997. Fiquei muito contente pelo reconhecimento da sua relevância para as mudanças que, nessa altura, vieram a ser feitas. De facto, era essa a preocupação. 0 estudo do distrito de Santarém ajudou a perceber muitos problemas que se passavam a nível nacional.

A reforma de 1997 decorreu quando estava a Teresa Vasconcelos, como diretora do Básico, em um momento em que estava o Partido Socialista no governo e havia pressões internacionais para o desenvolvimento da educação pré-escolar. Ainda durante o governo anterior, com o Partido Social Democrático no poder, recordo ter ido a reuniões para discutir a necessidade de serem definidas orientações curriculares para o pré-escolar. Pediam para dar a minha opinião pelos trabalhos que tinha realizado.

A par da necessidade de serem definidas orientações curriculares, discutia-se sobre o desenvolvimento da rede de jardins de infância e sobre a necessidade de o Ministério da Educação assumir a tutela pedagógica de toda a rede institucional. Esta reforma surge em grande parte na sequência do parecer do Conselho Nacional de Educação feito pelo Prof. João Formosinho. Com o novo governo socialista, com a Teresa Vasconcelos na direção do Básico e com o professor Marçal Grilo como ministro da Educação, ficaram reunidas as condições para a reforma da Educação Pré-escolar. Esta reforma foi muito importante.

Foi aprovada uma Lei Quadro (1997), definindo que a educação pré-escolar é a primeira etapa da educação básica e que a sua tutela pedagógica é competência do 
Ministério da Educação. Foram também definidas as Orientações Curriculares, trabalho que foi coordenado pela Isabel Lopes da Silva, com a equipe do Ministério. Participei neste trabalho como docente da ESE e, posteriormente, como presidente da APEI (Associação de Profissionais de Educação de Infância). Candidatei-me a presidente da APEI, depois de um desafio que me fizeram e porque achei que era um desafio importante na sequência do que tinha feito.

Nessa mesma altura, havia a preocupação com a formação dos educadores e educadoras, que essa passasse a ser uma licenciatura, como já acontecia com outros níveis de ensino. Já se falava de Bolonha, mas o Processo de Bolonha foi mais tarde. E, claro, continuava a preocupação com as questões das mulheres e da infância, com a conciliação entre a vida familiar e profissional. A minha proximidade com a CIDM deu outra vitalidade a esta reflexão.

A publicação da Lei Quadro da Educação Pré-escolar, as Orientações Curriculares, as mudanças a nível da formação foram um período de grande entusiasmo. Nós até dizíamos que era um novo 25 de abril! E, de facto, foi para a Educação de Infância depois de tudo ter andado tão embrulhado. Foi o início de uma reorganização do seu desenvolvimento.

Nesta altura, comecei a ter também uma relação mais estreita e muito próxima com a CIG [na altura CIDM], no projeto que se chamou Coeducação. Ainda houve um projeto anterior para a formação, que não teve continuidade. No projeto Coeducação, participei com um grupo de colegas da ESE de Santarém. Foi quando comecei a pensar mais seriamente a respeito de como trabalhar as questões de género na Educação de Infância. Foi o nosso primeiro trabalho nesta área. Foi a minha primeira formação e sensibilização para trabalhar as questões de género nas primeiras idades. Era um projeto internacional, estavam pessoas de diversos países. Mas a respeito do trabalho com as primeiras idades, só ficámos nós, da ESE de Santarém e as colegas da ESE de Beja. 0 resto dos parceiros ficou mais focado na formação para a educação de adultos ou para o ensino secundário.

\section{Então, sua aproximação com a CIG aumentou ali na altura do Coeducação?}

Aumentou. Mas já vinha de trás, desde o PROCEPE, e das minhas idas ao Centro de Documentação, da CIG, que era muito bom. Mas foi com o Coeducação que começou uma relação mais formal e foi quando conheci mais pessoas da Comissão. Aprendi muito.

Do ponto de vista da política pública de gênero, e pensando que a Comissão para a Cidadania e Igualdade de Gênero é um instrumento para fazer acontecer essa política e considerando também que a educação sempre foi uma área estratégica de atuação dessa Comissão, como você avalia o papel da CIG para a inserção de gênero na Educação de Infância?

Informalmente, já conhecia as atuações da Comissão desde que comecei a trabalhar na formação. Comecei a trabalhar muito cedo na formação de professores. Ainda antes da criação das Escolas Superiores de Educação. Quando eu acabei psicologia, fui trabalhar no magistério primário. Foi aí o meu primeiro contacto, porque a CIG dava apoio à formação inicial. Gostava 
de ir às reuniões, gostava de ler as publicações que distribuíam, foi o meu primeiro contacto. Depois, mais tarde, foi durante o PROCEPE que eu me aproximei mais. Mas sempre tive a noção de que havia projectos de intervenção e documentos de apoio muito interessantes e que me eram muito úteis como professora, como educadora e como formadora.

Recordo um documento, em particular, que foi muito importante para mim, a respeito da organização do ambiente educativo na educação pré-escolar. Aliás, no Coeducação, nós oferecemo-nos para fazer a adaptação e a actualização deste documento. Como já era antigo, acabámos por optar em fazer um novo até por sugestão das colegas da CIG. Mas havia, de facto, uma grande preocupação em termos da Educação e da formação. Para mim, a relação com a CIG sempre foi muito importante. Senti que, ao longo do tempo, houve uma evolução no sentido de uma maior sensibilização para o trabalho com as primeiras idades. É com os pequeninos e com as pequeninas que se começa. E acho que ainda precisava haver mais iniciativas.

E quais foram os projetos, especificamente, para a Educação de Infância, realizados pela CIG, em parceria ou não com o Ministério da Educação, dos quais você participou?

Tenho tido vários projectos, com o Ministério da Educação. Por exemplo, quando era presidente da APEI, participava mais como consultora, mas também como docente da ESE de Santarém. Uma pessoa tem sempre vários papeis e vários estatutos que determinam vários tipos de participação. Com a CIG, participei sempre mais como formadora e como educadora, sempre na área da Educação. Por exemplo, no projecto Coeducação, publicámos um livro e artigos que foram divulgados pela CIG. Como era um projecto financiado pela União Europeia, não necessitava muito do Ministério da Educação, mas, lógico que nós, como trabalhávamos em contacto com as pessoas, os livros chegaram ao Ministério da Educação.

Um projecto que envolveu estas duas instituições foi a construção dos Guiões. Este projeto surgiu na sequência do Fórum de Educação para a Cidadania, organizado de 2006 a 2008 por iniciativa do Conselho de Ministros - a CIG está ligada ao Conselho de Ministros. Convidaram pessoas de vários Ministérios e de várias organizações da sociedade civil e também convidaram a mim. Eu sempre trabalhei muito com África e com o Brasil e, na altura, estava em África e disseram para eu vir depressa, porque ia ser a primeira a apresentar uma intervenção. Depois, percebi que a preocupação era uma maior sensibilização para que todos os trabalhos que fossem feitos começassem na infância. Fiquei contente, porque anos atrás isso não era prioridade, ou pelo menos, eu não sentia que fosse uma prioridade. Foi uma conquista que foi sendo feita ao longo do tempo.

Nós podemos dizer que, de fato, a dimensão de gênero se insere nas políticas educativas?

Eu não posso dizer que não se insere, mas também não se pode dizer que está bem inserida. Acho que, de facto, fala-se em igualdade de oportunidades e de participação, mas de uma forma muito genérica. Fala-se de uma forma tão genérica que as questões de género muitas vezes acabam por se perder. Acho que no âmbito nacional ainda há 
um caminho grande a percorrer, mesmo com o trabalho que já foi feito. Esse projeto dos Guiões foi reconhecido na Europa, foi muito importante, mas ainda há muito a fazer.

Também há sempre muitas mudanças que não ajudam a continuidade e a consolidação do que se vai fazendo. A CIG é um organismo de caráter político, depende do governo. Vai mudando conforme a presidente, de modo que os trabalhos que se iniciam nem sempre são continuados. Faltam muitas coisas, nomeadamente, existir mais articulação com o Ministério de Educação.

Penso que foi um avanço muito importante a construção dos Guiões de género e cidadania. Eu coordenei o do pré-escolar e o do $1^{\circ}$ ciclo. Vou-me centrar só nesses, mas, neste momento, já há Guiões até o ensino secundário. Em termos do pré-escolar e do $1^{\circ}$ ciclo, eu acho que as coisas correram bem. Foram e estão a ser feitas muitas horas de formação a nível nacional. Mas não chega. Faz falta a criação de mais recursos para além dos Guiões. Por exemplo, para trabalhar com as crianças. Foi traduzido um baralho de cartas e há outros materiais construídos pelas educadoras e professoras durante a formação. Mas acho que tem de haver muito mais, até em suporte digital. E também se devia dar outra visibilidade ao que tem vindo a ser feito assim como uma maior monitoração nas escolas e jardins de infância.

Acho que faltam Guiões para trabalhar essas questões no âmbito das direções das escolas, por exemplo. Como é que entram os projectos de género e cidadania se o diretor ou a diretora da escola não deixa ou não apoia? A nível da formação inicial começa-se, mas a nível da formação contínua acho que não é suficiente a existência de ações de curta duração. E não é através de um livro que se faz a mudança. São necessários mais projectos em articulação com as instituições de formação e mais centrados nas escolas. Por exemplo, nós temos estagiários e estagiárias nas escolas, dos vários níveis de ensino. Devíamos ter condições para dar às escolas e jardins de infância um apoio mais continuado e mais aprofundado a respeito das questões de género e cidadania.

Neste momento, o Ministério está a tentar implementar uma estratégia nacional de Educação para a Cidadania a nível nacional. Mas educação para a cidadania abordada de forma tão genérica sem um apoio formativo centrado nas instituições acaba por não conseguir ter grandes resultados.

Estão a decorrer muitas ações de formação contínua, com cursos de curta duração, mas deveria existir um apoio mais centrado nas dificuldades das escolas. Em vez de virem à formação, devíamos estar nós nas escolas a apoiar o que fazem tendo em conta as suas reais necessidades.

Uma formação em contexto. E em relação à formação inicial, há nos currículos uma disciplina que insere gênero na formação de estudantes?

Nós temos. Eu acho que a maioria das ESEs, neste momento, tem uma disciplina de Educação para a Cidadania, em que o trabalho sobre as questões de género é um ponto importante. Nós temos as disciplinas de Educação para a Cidadania e a de Formação Pessoal e Social, que acabam por se completar. Temos ainda uma disciplina de opção de Filosofia para crianças em que os exemplos trabalhados são muito centrados nas questões de género e cidadania. 
Desde que os Guiões ficaram prontos, foi organizada uma rede de formadoras e formadores das ESEs, além das Universidades, se bem que a formação para as primeiras idades está mais centrada nas ESEs. Agora, se é eficaz, se é suficiente, o trabalho de formação que tem sido feito, não sei, depende, varia muito. Os cursos de formação inicial, desde a última revisão feita, ficaram muito mais teóricos, com menos tempo de estágio e menos horas para disciplinas das Ciências da Educação. Há poucas horas, mas penso que género e cidadania estão a ser trabalhados na maioria das instituições. Mas o trabalho destas questões, a nível da formação inicial, não chega. Há uma sensibilização. Mas tem de ser depois, na prática, quando começam a trabalhar com as colegas que este trabalho deve ser continuado. Há muitas estudantes que escolhem esta temática para as pesquisas dos trabalhos finais de curso. Estou a falar no feminino, porque práticamente só temos raparigas nos cursos de formação inicial.

Voltando à construção dos Guiões. Eles foram construídos para todos os níveis da Educação Básica e têm uma parte comum e uma parte específica. Quais foram as opções teórico-metodológicas assumidas?

A parte teórica foi feita por um equipa que tem investigação e doutoramento, especificamente, sobre género e cidadania. Houve algumas reuniões, discutimos as questões. A minha preocupação foi muito que houvesse uma clara definição de conceitos, porque acho que as pessoas se confundem muito. Até definir o que é género, o que é sexualidade, as pessoas confundem muito. E depois, também, procurámos que a abordagem fosse sempre feita em uma perspectiva de Educação para a Cidadania. Acho que isso foi bem conseguido.

Procurámos que em todos os Guiões houvesse uma parte teórica, uma parte teóricoprática, relacionada com as características do nível de ensino, e uma parte mais prática com muitas sugestões de trabalho que foram recolhidas durante os estágios e através de grupos de formação, organizados com essa finalidade, com docentes da educação pré-escolar e do $1^{\circ}$ ciclo do ensino básico. Os Guiões foram concebidos para que as suas diferentes partes pudessem ser lidas ou consultadas separadamente. Na parte prática dos Guiões construídos para a educação pré-escolar e para o $1^{\circ}$ ciclo do ensino básico, demos um grande relevo ao recurso da filosofia para crianças por nos parecer que era uma metodologia que nos oferecia melhores possibilidades de trabalho. Mais do que propor soluções, a grande finalidade destes Guiões foi promover uma atitude mais crítica, sendo sugeridos muitos instrumentos de análise para um questionamento do trabalho realizado e a realizar com as crianças, e também com as famílias e com a equipa de trabalho da escola ou do jardim de infância.

Ao analisarmos a parte teórica e o próprio título do material, observamos que gênero é inserido numa perspectiva de educação para a cidadania. Você poderia nos explicitar quais foram os princípios teórico-político-metodológicos para esta escolha? Em uma permanente tensão entre o geral e o específico, atrelar gênero ao debate mais amplo da cidadania não o invisibiliza? 
Penso que não. Penso que uma leitura atenta dos Guiões deixa isso bem claro. Acho que não se corre esse risco. E falar de género só me faz sentido em uma perspectiva de educação para a cidadania.

Neste momento, na construção da Estratégia nacional de educação para a cidadania, de que já falei, temo que esse risco surja. Fala-se de cidadania, no geral, e depois há vários referenciais e documentos de apoio. Acho que são demais! Mais de 20, cada um com apresentação de linhas de orientação que vão do pré-escolar ao secundário. Um deles é especificamente sobre o género e há uma referência à utilização dos Guiões.

Mas nos Guiões não há o risco de o género ficar invisível, perante a abordagem das questões da educação para a cidadania. Neste novo referencial que tem uma abordagem tão diversificada, esse risco pode existir. Se bem que o género está subjacente a todas as questões da educação para a cidadania. Como dizemos, em Portugal: "estão a querer meter o Rossio na Rua da Betesga”. 0 Rossio é muito grande e a Rua da Betesga é muito pequenina.

Em relação a essas temáticas, para nós, no Brasil, a articulação entre gênero e sexualidade, apesar de serem conceitos diferentes, estão muito relacionadas. Mas, olhando tanto para os Guiões quanto para a Estratégia Nacional de Educação para a Cidadania, não tem essa articulação, não tem um debate sobre diversidade sexual e orientação sexual. Você considera que foi uma opção da equipe ou é uma lacuna?

Os Guiões foram escritos para os educadores e educadoras, com exemplos de trabalhos com as crianças e falamos muito da diversidade, das diferentes orientações sexuais que se podem encontrar a nível das famílias. Podia ter sido mais desenvolvido. Também tenho de ser sincera, nós tínhamos limite de páginas, fizemos opções. Essas questões podiam ser desenvolvidas em uma nova publicação, por exemplo. Eu daria continuidade aos Guiões para, por exemplo, trabalhar a diversidade familiar. A respeito da sexualidade, talvez para o ensino básico [ $1^{\circ}$ ao $3^{\circ}$ ciclos]. Para os mais pequeninos, eu acho suficiente o que está nos Guiões. Mas trabalhar com as famílias é um dos aspectos que não conseguimos aprofundar mais e que precisa ser mais desenvolvido.

Outro aspecto a ser inserido seria o trabalho com as direções das instituições. Outro, com as autarquias e com as pessoas da comunidade. Outro, por exemplo, sobre a Educação Especial, em que há vários técnicos e técnicas que, muitas vezes, não são nada sensíveis para estas questões. Também acho que faz muita falta levar essas questões da sexualidade para o ensino profissional e também construir materiais a partir desses Guiões para poderem ser utilizados com as crianças e jovens.

Em relação à avaliação da política para a Educação de Infância, o que avançou? E quais são os desafios?

Nós podemos ser críticos, críticas, mas tem evoluído muita coisa! Por exemplo, houve uma altura em que eu estive na direção do Instituto Politécnico de Santarém e me afastei por uns anos dos estágios e das visitas a jardins de infância. Estava cheia de saudades quando voltei. Recordo que achei que tinha havido uma evolução enorme. Falo 
de Santarém, das instituições com que habitualmente trabalhamos. Foi tão bom! Agora, eu estou outra vez a achar que as coisas podiam estar a correr melhor. Mas é evidente que tem havido uma evolução. Para isso, foi muito importante terem passado a existir as Orientações Curriculares. As primeiras, como já disse, foram publicadas em 1997 e foram agora atualizadas em 2016. Também houve formação e outras publicações apoiadas pelo Ministério. Não foram só os Guiões do género e da cidadania, foram construídas brochuras de apoio para as várias áreas curriculares, sempre acompanhadas por formação.

Foi muito importante que estas publicações tenham sido sempre acompanhadas por formação. Por exemplo, a formação que correu melhor foi aquela que fizemos com as cooperantes [professoras que recebem estagiárias/os]. Foi a que correu melhor, porque tinha uma continuidade. Claro que também depende muito das pessoas e das suas motivações. Mas acho que apenas uma formação de curta duração ou um livro não chega. É necessário um apoio mais continuado. E a nível nacional nem sempre toda a gente tem acesso à formação.

Relativamente ao género e cidadania, a par de ter de se pensar na construção de novos materiais e em um maior apoio formativo, penso que também faz falta mais investigação. Temos de estudar mais profundamente como é que se trabalham estas questões no jardim de infância e na escola, além, também, na formação. Como já referi, tudo o que fizemos foi construído a partir de observações e recolhas de dados junto das crianças e de profissionais que estão no terreno. Nas diversas ações de formação que fazemos e também na formação inicial, durante os estágios, continuamos a recolher dados. E estamos sempre a aprender!

Aprendemos, por exemplo, que o início da formação nunca é fácil, as pessoas, mesmo as mais motivadas, têm tendência a dizer: "Ah, essas questões já estão ultrapassadas” e oferecem alguma resistência. É quando vão entrevistar as crianças com quem trabalham que a atitude muda e a formação começa! É sempre uma admiração com as respostas estereotipadas que as crianças dão, mesmo as mais pequeninas. Os trabalhos de pesquisa, os materiais construídos, tanto na formação inicial como na formação contínua têm sido também importantes contributos. Mas nem todos temos conseguido publicar e divulgar.

Acho que há um trabalho de pesquisa que precisa ser feito. Ainda sabemos muito pouco. Penso que o desenvolvimento de mais investigação nesta área é fundamental e gostaria de que houvesse mais apoio da CIG nesse sentido, assim como no apoio à realização de novas publicações. Por exemplo, sugeri às colegas da CIG, na sequência de um projecto internacional que vi ser apresentado na Universidade de Chipre, a realização de um estudo a respeito de como trabalhar com as crianças de famílias em que existe violência doméstica. Existem trabalhos feitos na área da psicologia, mas sem uma dimensão pedagógica. Trata-se de uma dificuldade sentida pelos educadores e professores. Como é que uma criança vê a mãe ser espancada ou vê cenas de violência entre o casal e no outro dia vai para a escola? Ou é violenta ou põe-se em um canto. E depois, como é que os professores e as professoras lidam com esse assunto? É um drama, uma grande dificuldade e não há respostas únicas.

Em Chipre, as professoras e professores pediram ajuda, precisavam de apoio para lidar com situações complicadíssimas que viviam. Mas a equipa era formada por psicólogas e a nível pedagógico não sabiam dar resposta. Mais tarde, a CIG traduziu um livro a 
respeito dessa problemática, mas é diferente, não é suficiente, estas publicações têm de ser feitas de acordo com o contexto. É diferente a realidade de um país do norte da Europa da realidade de Portugal, há uma dimensão cultural que tem de ser estudada previamente para saber quais as respostas mais adequadas.

Voltando à avaliação das políticas, como já disse, acho que há uma evolução. E também não nos podemos esquecer de uma questão que tem a ver com a própria evolução do país. A diversidade sociocultural das crianças é cada vez maior, temos cada vez mais imigrantes, temos também uma camada de crianças de famílias mais carenciadas que antigamente não ia ao jardim de infância e agora vai. Há novos desafios que nos questionam e que têm de começar a ser refletidos desde a formação inicial. As educadoras e educadores têm de saber acolher todas as crianças, aprender a ouvi-las, a ter práticas educativas diferenciadas e mais inclusivas. Mas uma coisa é o discurso, outra coisa são as práticas. Estamos sempre a ter de aprender! Tem de existir uma constante evolução. Neste sentido, tenho aprendido muito no trabalho que realizo com outros países, como docente, consultora investigadora.

Por exemplo, os projectos europeus dos quais tenho participado têm sido uma boa base de aprendizagem e de reflexão, entre outros aspetos em consequência da grande diversidade que caracteriza os diferentes países europeus! 0 trabalho que tenho feito no Brasil e com colegas do Brasil tem sido também muito importante. Há muita investigação sobre a educação de infância de muita qualidade no Brasil. E também o que aprendo com os trabalhos que tenho feito em África. Cheguei esta semana da Guiné-Bissau. Estive lá a dar aulas, mas também aprendi muito com os professores e professoras com quem estive. Quando saímos do nosso país, aprendemos sempre muito. Aprendemos a ter uma visão mais distanciada e crítica. Aprendemos a valorizar a diversidade das perspetivas. A nível sóciopolítico, por exemplo, que é uma área de que gosto muito, tenho aprendido como pequenos atos de gestão podem ter consequências enormes, mesmo sem que os legisladores tenham consciência destas implicações.

Precisava de ter mais tempo para a investigação e sistematização do que faço. Mas infelizmente, em Portugal, o ensino superior está mal organizado. As instituições como a minha, que trabalham na formação para as primeiras idades, estão maioritariamente centradas no ensino superior politécnico que tem menos dinheiro e tempo para apoio a trabalhos de investigação. 0 que nos obriga, muitas vezes, a ter de colaborar com universidades. Não faz muito sentido.

Nós gostariamos de conversar ainda sobre algumas questões particulares do contexto educacional brasileiro. Assistimos atualmente a um forte discurso de setores religiosos conservadores em defesa da supressão dos temas de gênero, diversidade e orientação sexual nos planos nacional, estaduais e municipais de Educação. Para justificar essa exclusão, utilizam o pseudoconceito da "ideologia de gênero", que ensinaria as crianças a não ter pertencimento identitário e acabaria com as famílias, criando um verdadeiro pânico em relação a essa temática. Considerando sua proximidade com o Brasil e sua experiência na construção de políticas públicas que articulam educação de 
infância e gênero em Portugal, como analisa a possibilidade de articulação de infância e gênero na realidade brasileira?

Eu acho que vocês têm realidades tão diferentes. Eu estou aqui a falar de diversidade sociocultural em relação a Portugal que é um país tão pequenino. Eu acho que não se pode falar do Brasil como um todo. Do que eu conheço do Brasil, e não conheço assim tão bem, ou o que conheço é mais através da universidade, penso que em termos de investigação há muito trabalho de grande qualidade sobre a educação de infância e na área do género também conheço vários trabalhos. Mas sinto que este investimento a nível de investigação não tem tido implicações evidentes na realidade das escolas e jardins de infância, nem a nível da formação. Tenho sentido um grande distanciamento entre a universidade e as escolas.

Uma coisa são as escolinhas que pertencem à universidade - não sei se ainda existem, já sei que infelizmente estão a deixar de existir. Por exemplo, na Universidade Estadual Paulista - UNESP, visitei várias e funcionavam muito bem. Mas outra coisa é entrar na rede, cá fora, e ver situações muito diferentes, às vezes com pessoas que nem formação têm ou têm apenas uma professora com formação. Parece-me que existe uma grande disparidade. Parece-me que era importante uma maior articulação entre teoria e prática, ou entre o saber académico e o saber dos profissionais que trabalham nas instituições educativas. Sei que há muitas pessoas ligadas à prática a fazer investigação, doutoramentos. Mas pelo que tenho visto muitas depois não regressam às escolas.

Mas acho que há muitos Brasis no Brasil. Se calhar, as mudanças têm de ser feitas no âmbito estadual. Mas mesmo assim só o estado de São Paulo é um mundo, não é? E sinto que há situações de conflitualidade entre o federal e o estadual que para quem está de fora como eu parecem extremamente complexas e difíceis de ultrapassar.

Quanto ao trabalho a respeito das questões de género, alguns exemplos que já ouvi apresentar parecem-se revelar dificuldades mais profundas do que as que sinto aqui: por exemplo, os rapazes não poderem brincar com bonecas ou as raparigas jogarem bola no jardim de infância. Claro que são situações que em Portugal também se colocam! Mas na educação de infância já não com tanta frequência e intensidade como vi relatar no Brasil. Penso que para que haja uma evolução, todas as crianças têm de poder ter acesso à educação de infância, com profissionais com formação e apoiados pelas universidades e/ou institutos federais.

Para finalizar, você gostaria de comentar mais algum aspecto ainda não abordado?

Eu acho que as políticas de género e de educação não podem estar separadas. Falamos da CIG e falamos do Ministério da Educação. Acho que as duas instituições têm de trabalhar em conjunto. Se calhar, o Ministério da Educação tem de integrar pessoas da CIG para existir mais articulação. Não se pode falar de política de género sem valorizar a perspetiva educativa. Posso fazer estudos, trabalhos muito teóricos, mas tenho de envolver educadores e educadoras para existir implicações na prática. E também me parece que as questões de género têm de ser trabalhadas numa perspetiva integrada de educação para 
a cidadania. Como sugerimos nos Guiões, há duas formas de intervenção que educadores e educadoras podem seguir: intervir para resolver situações que naturalmente acontecem no dia a dia do grupo e que não podem ser ignoradas; intervir através da proposta de atividades previamente planeadas em que existe uma clara intencionalidade educativa de trabalhar as questões de género com as crianças.

Não há soluções perfeitas. São áreas de intervenção muito complexas e de difícil intervenção. Há muito trabalho já feito, mas ainda há muito a fazer. Como já referi, pareceme fundamental investir em um apoio formativo mais contextualizado e aprofundado e não só em cursos de curta duração como está a acontecer. Nesse sentido, a articulação entre a formação inicial e contínua é uma forma privilegiada de dar continuidade ao que é feito nas formações de curta duração. É também importante continuar a construir novos guias e materiais de apoio, o que tem de passar obrigatoriamente por um maior apoio à investigação nesta área.

Para terminar, se calhar, escolho uma frase do vosso Paulo Freire que inserimos no Guião do $1^{\circ}$ ciclo, por nos parecer que sublinha bem de forma metafórica os motivos que nos levaram a desenvolver este projecto.

O conhecimento sobre os terramotos desenvolveu toda uma engenharia que nos ajuda a sobreviver a eles. Não podemos eliminá-los mas podemos diminuir os danos que nos causam. Constatando, nos tornamos capazes de intervir na realidade, tarefa incomparavelmente mais complexa e geradora de novos saberes do que simplesmente a de nos adaptar a ela [...].

Ninguém pode estar no mundo, com o mundo e com os outros de forma neutra. Não posso estar no mundo de luvas nas mãos constatando apenas. A acomodação em mim é apenas caminho para a inserção, que implica decisão, escolha, intervenção na realidade. (FREIRE, 2005, p. 77).

\section{Referências}

FREIRE, Paulo. Pedagogia da autonomia: saberes necessários à prática educativa. São Paulo: Paz e Terra, 2005.

\section{Publicações recentes da entrevistada}

BOTELHO, Irina; CARDONA, Maria João. A influência das questões de género nos resultados escolares das crianças. Revista da UIIPS, Santarém, v. 2, n. 6, p. 68-86. dez. 2014. Disponível em: <http://www. ipsantarem.pt/arquivo/category/unidades/unidade-de-investigacao-uiips/publicacoes $>$. Acesso em: 13 out. 2018.

CARDONA, Maria João. A avaliação na educação de infância: dificuldades e dilemas l'évaluation à la maternelle. difficultes et dilemmes. In: COLÓQUIO DA AFIRSE PORTUGAL, 22., 2015, Lisboa. Anais... Lisboa: EDUCA AFIRSE, 2015. Disponível em: <http://afirse.ie.ul.pt/atas-online/>. Acesso em: 13 out. 2018.

CARDONA, Maria João. A educação de infância: primeira etapa no processo de formação ao longo da vida. In: PORTUGAL. Conselho Nacional de Educação. Organização do Sistema Educativo. Lei de bases do sistema educativo: balanço e prospetiva. v. 1. Lisboa: CNE, 2017. p. 361. Encontro Organização do Sistema Educativo. 
CARDONA, Maria João. A entrada do sexo masculino na educação de infância: a perspetiva de algumas educadoras. Cadernos de Educação de Infância, Lisboa, n. 101, p. 10-14, 2014.

CARDONA, Maria João. A formação dos diretores e diretoras para o desenvolvimento qualitativo das escolas: um projeto que está a ser desenvolvido em São Tomé e Príncipe. In: COLÓQUIO DE CURRÍCULO, 11. / COLÓQUIO LUSO-BRASILEIRO, 7. / COLÓQUIO LUSO-AFRO-BRASILEIRO DE CURRÍCULO, 1., 2014, Braga. Anais... Braga: Universidade do Minho. p. 1135-1141. Disponível em: <http://repositorium.sdum. uminho.pt/handle/1822/30984>. Acesso em: 13 out. 2018.

CARDONA, Maria João. As escolas como espaços de desenvolvimento comunitário: um estudo baseado na experiência de São Tomé e Príncipe. In: EUROPEAN CONFERENCE ON AFRICAN STUDIES (ECAS) - AFRICAN DYNAMICS IN MULTIPOLAR WORLD, 5., 2014, Lisboa. Anais... Lisboa: ISCTE - CEI, 2014. p. 516-528. Disponível em: <https://repositorio.iscte-iul.pt/browse?type=author\&order=ASC\&rpp=20\&value=Cardon a\%2C+Maria+Jo\%C3\%A30>. Acesso em: 13 out. 2018.

CARDONA, Maria João. Infâncias e modelos de educação de infância. In: II SEMINÁRIO LUSO-BRASILEIRO DE EDUCAÇÃO DE INFÂNCIA, 2., 2016, Braga. Investigação, formação docente e culturas de infância. Braga: Universidade do Minho, 2016. Disponível em: <http://www.whitebooks.pt/pdf/Atas-II-SLBEl-26maio-2017_v5.pdf>. Acesso em: 13 out. 2018.

CARDONA, Maria João. 0 papel dos diretores e diretoras no desenvolvimento qualitativo das escolas: a importância da sua formação. In: COLÓQUIO DA SECÇÃO PORTUGUESA DA AFIRSE, 21., 2015, Lisboa. Educação, economia e território: o papel da educação no desenvolvimento: Anais... Lisboa: AFIRSE, 2015. Disponível em: <http://afirse.ie.ul.pt/atas-online/>. Acesso em: 13 out. 2018.

CARDONA, Maria João. Quinze anos depois: o impacto do doutoramento realizado em Caen. In: OLIVEIRA, Dolandina (Org.). Construindo investigação em ciências da educação: os doutoramentos portugueses com Louis Marmoz. Lisboa: Educa, 2018. p. 153-169.

CARDONA, Maria João. Recherche en éducation et réalités du monde scolaire. In: MARM0Z, Louis; MARMOZ, Raoul (Coord.) La recherche en éducation: pluralité et complexité, Paris: AFIRSE/Ed. L'Harmattan, p. 57-63, 2014.

CARDONA, Maria João. Trabalhar as questões de género desde a educação pré-escolar. Notícias. Coeducação. Percursos e Desafios, Lisboa, n. 90, p. 16-18, jan./jun. 2014. Disponível em: <http://www. igfse.pt/upload/docs/2014/Noticias_90_Coeduc_percursos_e_desafios.pdf >. Acesso em: 13 out. 2018.

CARDONA, Maria João. Trabalhar as questões de género numa perspetiva de educação para a cidadania no jardim-de-infância e na escola. Revista Aprender, Portalegre, n. 35, p. 63-72, 2015c.

CARDONA, Maria João; COLAÇO, Susana. Para uma pedagogia no ensino superior. Bases para um trabalho de intervenção. Revista da UIIPS, Santarém, v. 2, n. 6, p. 87-96, dez. 2014. Disponível em: <http://www. ipsantarem.pt/arquivo/category/unidades/unidade-de-investigacao-uiips/publicacoes. Acesso em: 13 out. 2018.

CARDONA, Maria João; PISCALHO, Isabel. Importância da formação para o desenvolvimento qualitativo das escolas: exemplo de um projeto que está a ser desenvolvido em São Tomé e Príncipe. In: CONGRESSO 
SPCE. Ciências da educação: espaços de investigação, reflexão e ação interdisciplinar, 12., 2014, Vila Real. Anais... Vila Real: UTAD, 2014. p. 2451-2459. Disponível em: <https://apps2.utad.pt/files/SPCE2_EIXOS_ B00K\%20CC.pdf>. Acesso em: 13 out. 2018.

CARDONA, Maria João; SANTOS, Leonor. Promover a aprendizagem cooperativa na educação pré-escolar: 0 que dizem as educadoras de infância. Revista da UIPSS, Santarém, v. 2, n. 2, p. 156, 2014. Disponível em: $<$ http://www.ipsantarem.pt/wp-content/uploads/2014/04/Revista-da-UIIPS_N1_Vol2_2014_RESUMOS. pdf>. Acesso em: 13 out. 2018.

CARDONA, Maria João; UVA, Marta. Trabalhar o género e a cidadania desde a educação pré-escolar: fundamentos, objetivos e exemplos de práticas. In: CONGRESSO SPCE. Ciências da educação: espaços de investigação, reflexão e ação interdisciplinar, 12., 2014, Vila Real. Anais... Vila Real: UTAD, 2014. p. 663-670. Disponível em: <https://apps2.utad.pt/files/SPCE2_EIXOS_BO0K\%20CC.pdf>. Acesso em: 13 out. 2018.

CARDONA, Maria João; UVA, Marta; PISCALHO, Isabel. Género e cidadania nas práticas educativas do jardim de infância e da escola: receios, dificuldades e dilemas In: COLÓQUIO DE CURRICULO, 11. I COLÓQUIO LUSO-BRASILEIRO, 7. / COLÓQUIO LUSO-AFRO-BRASILEIRO DE CURRÍCULO, 1., 2014, Braga. Anais... Braga: Universidade do Minho, 2014. p. 2938-2945. Disponível em: <http://repositorium.sdum. uminho.pt/handle/1822/30984>. Acesso em: 13 out. 2018.

CARDONA, Maria João; UVA, Marta; PISCALHO, Marta. Projecto de caracterização e intervenção em igualdade de oportunidades. Promover a igualdade de género na educação pré-escolar: a necessidade de intervir desde a formação inicial. In: COLÓQUIO DA AFIRSE, 18., 2010; Lisboa. Anais... Lisboa, Afirse-Universidade Lisboa, 2010. p. 1-9. Disponível em: <http://afirse.ie.ul.pt/atas-online/>. Acesso em: 13 out. 2018.

CARDONA, Maria João et al. Guião de educação: género e cidadania no pré-escolar. 2. ed. Lisboa: CIG, 2015a.

CARDONA, Maria João et al. Guião de educação: género e cidadania no $1^{\circ}$ ciclo do ensino básico. 2. ed. Lisboa: CIG, 2015b.

CARDONA, Maria João et al. Os guiões de educação género e cidadania na prática educativa: receios, dificuldades e dilemas. Revista da UIPSS, Santarém, v. 2, n. 2, p. 158, 2014. Disponível em: <http://www. ipsantarem.pt/wp-content/uploads/2014/04/Revista-da-UIIPS_N1_Vol2_2014_RESUMOS.pdf>. Acesso em: 13 out. 2018.

CARDONA, Maria João et al. Projecto europeu TODDLER - por oportunidades para crianças desfavorecidas e com necessidades educativas especiais durante os primeiros anos de vida. Revista da UIPSS, Santarém v. 2, n. 2, p. 169, 2014. Disponível em: <http://www.ipsantarem.pt/wp-content/uploads/2014/04/Revistada-UIIISS_N1_Vol2_2014_RESUMOS.pdf>.Acesso em: 13 out. 2018.

CARVALHO, Deolinda et al. A importância da formação dos diretores e diretoras para o desenvolvimento qualitativo das escolas: exemplo de um projeto que está a ser desenvolvido em São Tomé e Príncipe. Revista da UIPSS, Santarém, v. 2, n. 2, Informar p. 166, 2014. Disponível em: <http://www.ipsantarem.pt/wp-content/ uploads/2014/04/Revista-da-UIIPS_N1_Vol2_2014_RESUMOS.pdf>. Acesso em: 13 out. 2018. 
CLÉRIGO, Bruna et al. Estratégias de diferenciação pedagógica nas primeiras idades para a construção de uma prática inclusiva. Revista da UIIPS, Santarém, v. 5, n. 1, 2017. Disponível em: <http://ojs.ipsantarem.pt/index.php/REVUIIPS/issue/current>. Acesso em: 13 out. 2018.

GARCIA, Ana Paula; CARDONA, Maria João. 0 professor/educador como gestor da autoridade e dos afetos no processo de ensino-aprendizagem. Revista da UIIPS, Santarém, v. 3, n. 6, p. 135-150. 2015. Disponível em: <http://ojs.ipsantarem.pt/index.php/REVUIIPS/issue/view/8>. Acesso em: 13 out. 2018.

LOPES, Isabel; CARDONA, Maria João. Representações sociais de educadores de IPSS's sobre supervisão pedagógica. Revista da UIIPS, Santarém, v. 3, n. 6, p. 349-369, 2015. Disponível em: <http://ojs. ipsantarem.pt/index.php/REVUIIPS/issue/view/8>. Acesso em: 13 out. 2018.

MOURÃO, Lúcia; CARDONA, Maria João. Modelo de (auto)formação cooperada do MEM e supervisão pedagógica. Implicações nas práticas pedagógicas e no desenvolvimento profissional de educadores de infância. Revista da UIIPS, Santarém, v. 3, n. 6, p. 71-94, 2015. Disponível em: <http://ojs.ipsantarem.pt/ index.php/REVUIIPS/issue/view/8>. Acesso em: 13 out. 2018.

ROLO, Mónica Rolo; CARDONA, Maria João. A supervisão na educação de infância - estudos de caso na rede solidária. Revista da UIIPS, Santarém, v. 3, n. 6, p. 95-113, 2015. Disponível em: <http://ojs. ipsantarem.pt/index.php/REVUIIPS/issue/view/8>. Acesso em: 13 out. 2018.

\section{Publicações no Brasil}

CARDONA, Maria João. Educação pré-escolar ou pedagogia da educação de infância? Fundamentos e concepções subjacentes. Revista Nuances, Presidente Prudente, v. 20, n. 21, p. 144-162, 2011. Disponível em: <http://revista.fct.unesp.br/index.php/Nuances/article/viewFile/1102/1107>. Acesso em: 13 out. 2018.

CARDONA, Maria João. Falando de transições: entre a educação de infância e a escola. Revista Nuances, Presidente Prudente, v. 25, n. 2, p.311-322, maio/ago. 2014. Disponível em: <http://revista.fct.unesp.br/ index.php/Nuances/article/viewFile/2772/2700 >. Acesso em: 13 out. 2018.

CARDONA, Maria João. 0 espaço e o tempo no jardim de infância, Pro-Posições, Campinas, v. 10, n. 1 (28), p. 132-139, 1999.

CARDONA, Maria João. Planear e avaliar na educação pré-escolar: a realidade portuguesa das últimas décadas. Revista Linhas, Florianópolis, v. 18, n. 38, p. 143-159, 2017. Disponível em: <http://www. periodicos.udesc.br/index.php/linhas/issue/view/589>. Acesso em: 13 out. 2018.

CARDONA, Maria João et al. Projeto europeu: por oportunidades para crianças desfavorecidas e com necessidades educativas especiais durante os primeiros anos de vida. Revista Nuances, Presidente Prudente, v. 22, n. 23, p. 170-185, maio/ago. 2012. Disponível em: <http://revista.fct.unesp.br/index.php/ Nuances/article/viewFile/1766/1700>. Acesso em: 13 out. 2018.

GUIMARÃES, Célia Maria; CARDONA, Maria João (Org.). Dossiê Avaliação na Educação Infantil. Revista Nuances, Presidente Prudente, v. 25, n. 3, set./dez. 2014. Disponível em: <http://revista.fct.unesp.br/ index.php/Nuances/issue/view/231/showToc>. Acesso em: 13 out. 2018. 
GUIMARÃES, Célia Maria; CARDONA, Maria João; OLIVEIRA, Daniele Ramos (Coord.). Fundamentos e práticas da Avaliação na educação infantil. São Paulo: Mediação, 2014.

SOUSA, Ana Célia; CARDONA, Maria João; MADEIRA, Cristina. As relações desiguais de gênero e seu impacto na evasão escolar num curso técnico do IFB/Campus S. Brasília, DF: IFB. (no prelo).

TOTH, Larissa; CARDONA, Maria João; MADEIRA, Cristina. A influência do gênero no processo de evasão escolar. Brasília, DF: IFB. (no prelo).

\section{Outras publicações}

CARDONA, Maria João. Educação de infância: formação e desenvolvimento profissional, Chamusca: Cosmos, 2006.

CARDONA, Maria João. Genre et diversité culturelle: un grand défi pour l'école maternelle. Enfants de I'Europe, Bruxelles, n. 23, p. 20-22, oct. 2012. Publicado em todos os países da rede infância na Europa. Versão portuguesa: Género e diversidade cultural: um desafio para o jardim de infância. Revista Infância na Europa, n. 23, p. 23-26, 2012.

CARDONA, Maria João. Para a história da educação de infância em Portugal: 0 discurso oficial (18341990). Porto: Porto Editora, 1997.

CARDONA, Maria João; UVA, Marta; PISCALHO, Isabel. 0 papel do conflito no trabalho sobre as questões de género no jardim de infância e na escola. In: CONGRESSO DA SPCE - ESE DA GUARDA, 2011, Guarda. Anais... Guarda: SPCE, 2011. Informar p. 83-86. Disponível em: <http://www.ipg.pt/11congresso-spce/>. Acesso em: 13 out. 2018.

CARDONA, Maria João; UVA, Marta; PISCALHO, Isabel. The analytical tools to work gender-equality issues at the pedagogical practices and formative level. In: KUMPULAINEN, Kristina; TOOM, Auli (Ed.). ANNUAL CONFERENCE OF THE EUROPEAN TEACHER EDUCATION NETWORK ETEN, 22., 2012. Proceedings... [S. L.: s. n.], 2012. p. 101-108. Disponível em: <http://www.eten-online.org/modules/sjt_publications/>. Acesso em: 13 out. 2018.

CARDONA, Maria João et al. The role of the conflitct resolution in the work of gender's questions in the kindergarten and in primary school. Human Rights and Violent Behaviour: the social and educational perspective, Nicosia, p. 157-167, 2012.

PISCALHO, Isabel et al. To address gender equality since the preschool education: research and practices. Inauguration of the UNESCO Chair in Gender Equality and Women's Empowerment. INTERNATIONAL CONFERENCE MAPPING THE GENDER EQUALITY, 2010, Nicosia. Research and practices: the national and international perspective. Nicosia: University of Cyprus, 2010. p. 261-270.

PROCEPE. Um estudo sobre a educação de infância no distrito de Santarém: PROCEPE/ ESE. Santarém: Gulbenkian, 2000.

SILVA, Ana da. et al. La narrativa en la promoción de la igualdad de género. Aportaciones para la educaión pre-escolar: Projecto Coeducação. Lisboa, CIDM, 2006. 